$\mathrm{BNL}-65802$

\title{
Chemical imaging of living cells by synchrotron infrared microspectrometry
}

\author{
Nadège Jamin \\ CEA-DSV-DIEP \\ Saclay-F9191, Gif sur Yvette Cedex, France \\ Paul Dumas \\ LURE and LASIR-CNRS, Centre Universitaire Paris-Sud \\ F91405 Orsay Cedex, France \\ Janine Moncuit, W.H. Fridman, and Jean-Luc Teillaud \\ INSERM U., Institut Curie \\ F75248 Paris Cedex 04, France \\ G.L. Carr and G.P. Williams \\ NSLS, Brookhaven National Laboratory \\ Upton, NY 11973, USA
}

July 1997

\author{
National Synchrotron Light Source \\ Brookhaven National Laboratory \\ Operated by \\ Brookhaven Science Associates \\ Upton, NY 11973
}

Under Contract with the United States Department of Energy

Contract Number DE-AC02-98CH10886 


\section{DISCLAIMER}

This report was prepared as an account of work sponsored by an agency of the United States Government. Neither the United States Government nor any agency thereof, nor any of their employees, nor any of their contractors, subcontractors or their employees, makes any warranty, express or implied, or assumes any legal liability or responsibility for the accuracy, completeness, or any third party's use or the results of such use of any information, apparatus, product, or process disclosed, or represents that its use would not infringe privately owned rights. Reference herein to any specific commercial product, process, or service by trade name, trademark, manufacturer, or otherwise, does not necessarily constitute or imply its endorsement, recommendation, or favoring by the United States Government or any agency thereof or its contractors or subcontractors. The views and opinions of authors expressed herein do not necessarily state or reflect those of the United States Government or any agency thereof. 


\title{
Chemical imaging of living cells by synchroton infrared microspectrometry.
}

\author{
Nadège Jamin ${ }^{a}$, Paul Dumas ${ }^{b}$, Janine Moncuitc ${ }^{c}$, W.H. Fridman ${ }^{c}$, Jean-Luc Teillaudc, G.L. Carr ${ }^{d}$, \\ G. P. Williams . \\ a CEA-DSV-DIEP- Saclay-F9191 Gif sur Yvette Cedex \\ b LURE and LASIR- CNRS, Centre Universitaire Paris-Sud, F91405 Orsay Cedex \\ c INSERM U. 255, Institut Curie, F75248 Paris Cedex 05 \\ d NSLS Brookhaven National Laboratory, NY 11974 (USA)
}

\begin{abstract}
Chemical mapping of proteins and lipids inside a single living cell and at a resolution of a few microns, has been performed using synchroton infrared microspectrometry. Modifications of the chemical distributions upon mitosis and necrosis has been investigated.
\end{abstract}

Keywords: living cell, proteins, lipids, infrared, synchroton, microspectrometry

Individual ceils are quite small (10 to $30 \mu \mathrm{m}$ in cliameter) and their composition is complex. Their molecular composition is hardly determined and it is difficult to understand the function of the various components. What we can learn about cells depends on the probe technique. Numerous light microscopic techniques exist. Standard light microscopy (resolution up to $0.2 \mu \mathrm{m}$ ) utilizes fixed and stained cells while immunofluorescence microscopy reveals specific proteins and organelles. Transmission electron microscopy visualizes detailed structure of membrane and organelles (resolution up to 2 $\mathrm{nm}$ ) and scanning electron microscopy reveals the details on the outer shell of cells and particules. In this paper we demonstrate that molecular compound clistributions (proteins, lipids and nucleic acids) are obtained with a spatial resolution of few microns inside cells without the use of stains and fixatives using synchroton infrared microspectrometry.

Infrared spectroscopy is a well-established, non-destructive analytical tool which is extensively applied to identify chemical groups in compounds from different sources (physics, chemistry and biology) 1 . The identification of the chemical groups rely on the dependence of the positions, widths and strengths of the vibration modes of the molecule upon the chemical structure. The identification of the vibrational modes of the major compounds (nucleic acids, proteins, lipids) of biological tissues and cells has been performed using conventional Fourier transform infrared spectroscopy $2-4$. Thus infrared spectroscopy provides a mean to image chemical compounds inside the cells. The major challenge is to attain the appropriate spatial resolution as with conventional infrared microspectrometry only images of area greater than $100 \mu m^{2}$ are obtained with a sufficently good signal-to- noise ratio. It has recently been demonstrated that using the high brigthness of the synchroton source combined with a commercial doubly confocal microscope, resolution up to few microns are achieved 5,6 . We demonstrate hereafter, that detailed chemical images (in micron scale range) of individual cells are obtained using synchrotron infrared microspectrometry.

\section{MATERIALS AND METHODS}

UN2.C3 cells were derived from the mouse UN2 hybridoma B cells ${ }^{7}$. They were cultured in RPMI 1640 medium supplemented with $10 \% \mathrm{FCS}$, penicillin $(50 \mathrm{IU} / \mathrm{ml})$ and streptomycin $(50 \mathrm{mg} / \mathrm{ml})$. To record IR spectra, the cells were deposited on a transparent IR window (Barium fluoride, $\mathrm{BaF}_{2}$ ) by low speed cytospin centrifugation. Their viability was tested before and after recording the spectra using tryptan blue method.

IR spectra are recorded using a Spectra Tech Ir Synchroton Light Source (NSLS) at Brookhaven Nationial Laboratory. Spectra were recorded in transmission with an instrumental resolution of $4 \mathrm{~cm}^{-1}$ and 128 scans were co-added prior to Fourier transform processing. Each spectrum is ratioed to a reference one, recorded with the same parameters and conditions but outside the cell. After Fourier transform the spectra were processed according to the following procedure: 
-Linear baseline has been first substracted, in order to account for the continuous decay of the beam intensity inside the storage ring.

- Integrated intensity of the band or massif under consideration has been calculated. .

\section{RESULTS}

\section{Spectrum of a single cell}

The first step toward mapping chemical functions inside a cell lies in the ability to record IR spectra of high signalto-noise ratio within an area much smaller than the dimensions of a cell. Such a possibility is demonstrated here on figure 1 which displays a spectrum acquired with a transmitted beam collected through an aperture of $3 \times 3$ micron ${ }^{2}$ (about $1 / 100$ th of cell area). High signal-to-noise ratio spectrum is obtained in only 55s. This signal-to-noise ratio is severely reduced below $1200 \mathrm{~cm}^{-1}$ due to the combination of the diffraction effects (diffraction starts for a wavelength egal to the aperture size ) and the change of the reflective index of the material used as the substrate (in the present case : BaF2) . A compromise should be found between the desired resolution and the spectral region, because when using double confocal objectives, the lateral resolution will be kept the same for all the frequencies but at the expense of intensity loss for long waveiength. in addition, if there is any change of the reflective index of the substrate, the two apertures in the confocal configuration are not anylonger conjugated, resulting in a drastic loss of intensity at the detector (see figure 2 and discussion). In the present work, using an aperture size of $3 \times 3$ micron $^{2}$ and a $\mathrm{BaF}_{2}$ substrate, spectrum of high signal-to-noise ratio could be obtained up to about $1200 \mathrm{~cm}^{-1}(8.5 \mu \mathrm{m})$.

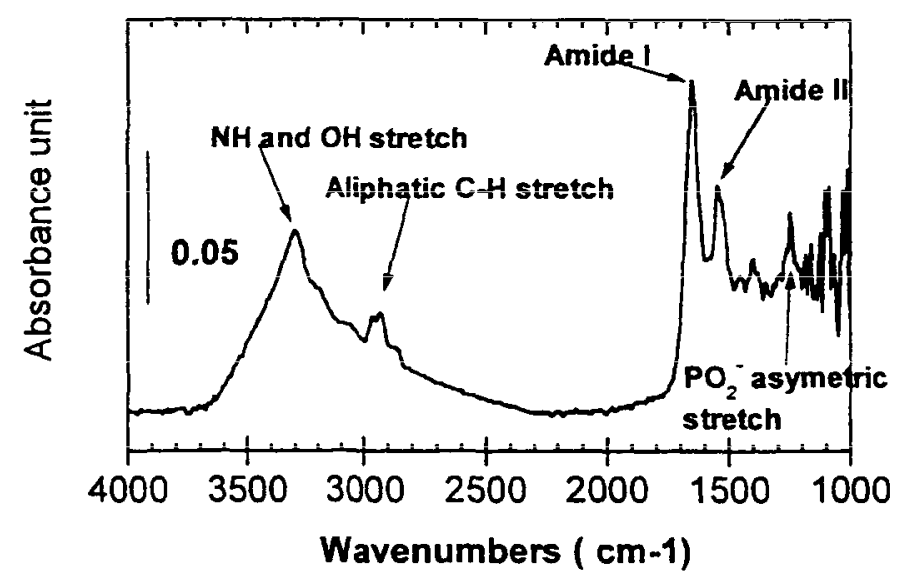

Figure 1 : Infrared spectrum of a mouse UN2 hybridoma B living cell, recorded with an aperture size of $3 \times 3 \mu \mathrm{m}^{2}$ (See Materials and methods).

The high complexity of the cell chemical composition results in the superposition of the absorption bands of the differents components of the cell and thus few large absorption bands are observed. Identification of each component is preciuded but the main chemical classes (proteins, nucleic acids, lipids ) can be identified through the assignment of one or more of the vibrational band of their characteristic functional groups. Assignments of these vibrational bands have been the subject of previous work $\mathrm{K}^{8=10}$.

The band at $1240 \mathrm{~cm}^{-1}$ originates from the asymetric stretching mode of phosphodiester groups ( $\left.\mathrm{PO}^{-}\right)$in nucleic acids.

The bands at $1545 \mathrm{~cm}^{-1}$ (amide II) and $1650 \mathrm{~cm}^{-1}$ (amide I) arise fom vibrations of amide groups of proteins. The $\mathrm{H}_{2} \mathrm{O}$ deformation band can also contribute to the intensity of the amide $\mathrm{I}$ band at $1650 \mathrm{~cm}^{-1}$. 
The bands in the $2850-2960 \mathrm{~cm}^{-1}$ region arise from symmetric and asymetric stretching modes of methylene $\left(\mathrm{CH}_{2}\right)$ and methyl $\left(\mathrm{CH}_{3}\right)$ groups found in proteirs and lipids.

The band at $3300 \mathrm{~cm}^{-1}$ originates from the vibrations of $\mathrm{OH}$ and $\mathrm{NH}$ groups $\left(\mathrm{H}_{2} \mathrm{O}\right.$, proteins and polysaccharides).

Thus it is possible to map unambiguously nucleic acids and proteins in cells by the analysis of the band at $1240 \mathrm{~cm}^{-1}$ and the amide II band at $1545 \mathrm{~cm}^{-1}$, respectively. Mapping the lipids will require that the $\mathrm{CH}_{2}$ and $\mathrm{CH}_{3}$ functional groups of proteins do not contribute significantly to the bands in the $2850-2960 \mathrm{~cm}^{-1}$ spectral region.

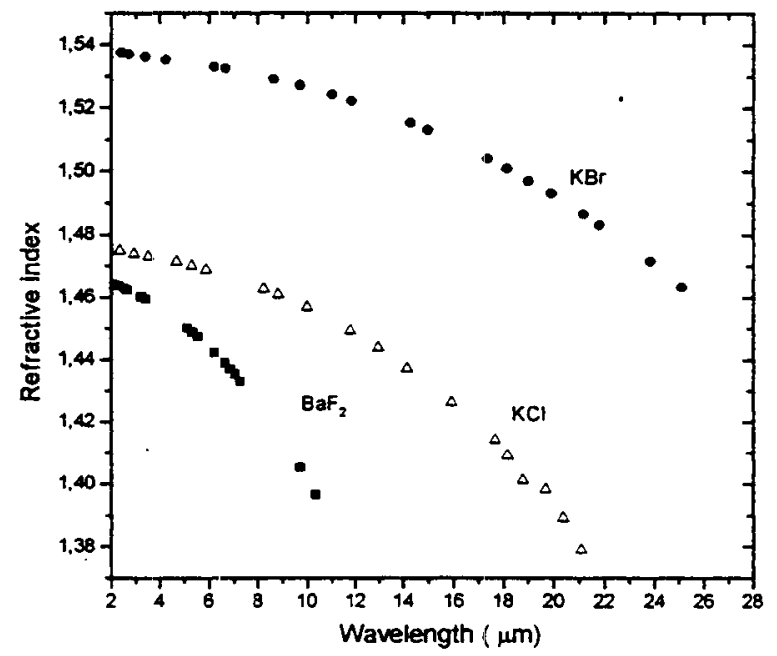

Figure 2. Curve of the refractive index versus the wavelength ${ }^{11}$.

\section{Linear mapping}

The next step toward chemical mapping is the ability to distinguish two close areas of the sample. To demonstrate this, we acquired a serie of spectra through an aperture of $3 \times 3$ micron $^{2}$, with a step of $1 \mu \mathrm{m}$ along an axis crossing a cluster of four cells, as pictured on figure 3 . The graphs on figure 4 display the value of the integrated intensity for each band versus the position of the beam. The concentration profile for each cell and inside each cell is well defined.

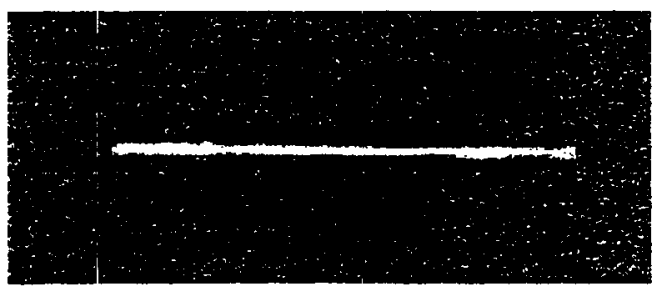

Figure 3: Optical image of the cells cluster mapped linearly 

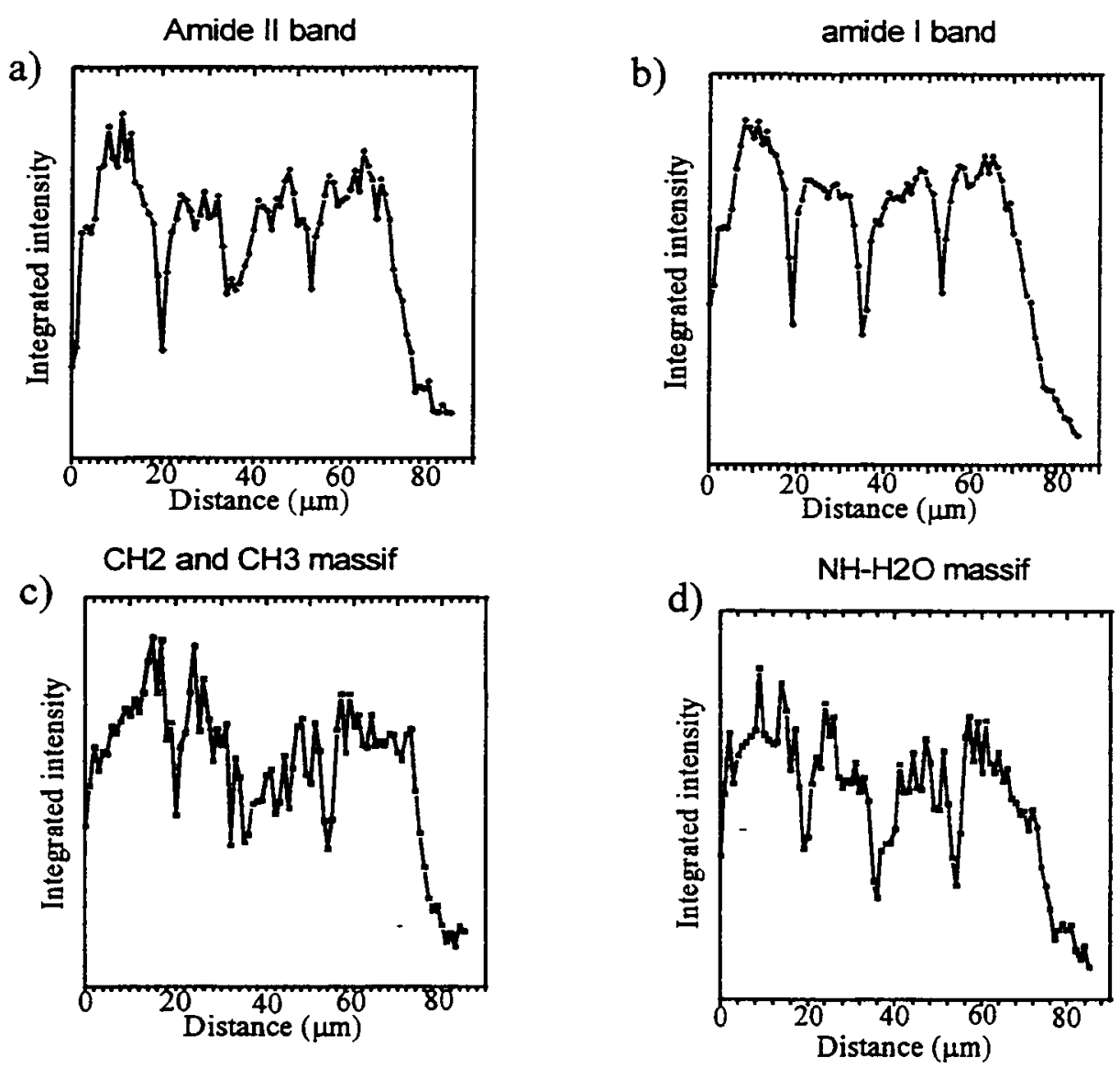

Figure 4. Linear mapping of a cluster of cells. Infrared spectra were recorded every $1 \mu \mathrm{m}$ along an axis crossing the four cells. a , b, c, d: Plots of the integrated intensity of respectively Amide II band, Amide I band, $\mathrm{CH}_{2}$ and $\mathrm{CH}_{3}$ massif, $\mathrm{NH}$ and $\mathrm{OH}$ massif, versus position of the beam.

\section{Chemical mapping of cells.}

We then acquired, in a raster fashion, a matrix of $14 \times 14$ spectra through an aperture of $3 \times 3$ micron ${ }^{2}$ stepping every $3 \mu \mathrm{m}$ of a single living cell. The distribution of the integrated intensity of the amide II band and the $\mathrm{CH}_{2}$ asymetric stretching band $\left(2929 \mathrm{~cm}^{-1}\right)$ of the cell is reported on figure 5 . The amide II band image is quite homogeneous and the intensity is maximum around the center of the cell. This is in agreement with the large size of the nucleus of this type of cell. In contrast, the distribution of the $\mathrm{CH}_{2}$ groups is non homogeneous and different than those of proteins which implies that it represents mainly the distribution of lipids inside the cells. This observation was made for all the different cells investigated. 


\section{A.Optical Image}
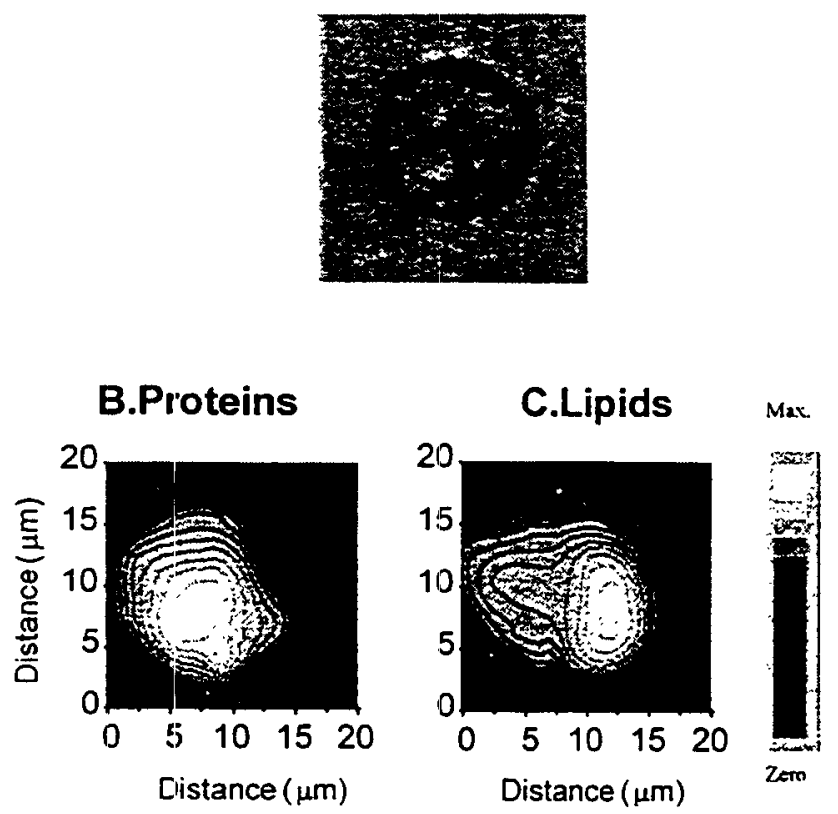

Figure 5. Chemical distribution of the proteins and lipids characteristics IR bands ( amide II and $\mathrm{CH} 2$ asymetric streching bands respectively). A: Optical image. B: Protein distribution. C: Lipid distribution. The mappings have been obtained by analysing the integrated intensity variation of a two-dimensional set of infrared spectra (14x14 points, step egal to $3 \mu \mathrm{m})$. Each spectrum was recorded in transmission through a $3 \times 3 \mu \mathrm{m}^{2}$ aperture.

The feasibility of mapping chemical classes of compounds open the way to study variations in the distribution of these compounds during biological events.

We studied proteins and lipids distributions in cells at late stages of mitosis. Figure 6a displays the optical image of a cell at the late telophase stage with an almost complete cytokinesis (left panel) and the optical image of cells which likely derive from a complete mitosis (right panel). For the cell at the late telophase stage, the protein distribution is spread out all over the cell but with maxima centered in the two regions which correspond to the daughter cells (Figure $6 \mathrm{~b}$, left panel). The lipids distribution is particularly high in the region where the contractile ring responsible for the cleavage furrow is located (Figure 6c, left panel). This could correspond to the inward pulling of the lipids by this contractile ring occuring in that region just before cell division. In contrast, when the cells are separated, the lipids and proteins distributions are similar to those observed in isolated cells (see Figures $6 \mathrm{c}$ and 5).

We have also studied the proteins and lipids distributions for cells undergoing necrosis. The IR spectrum of such a cell (Figure 7) shows broader bands than in the case of viable resulting from an increased heterogeneity of the sample. A new narrow band appears at $1730 \mathrm{~cm}^{-1}$ and is assigned to carbonyl ester groups, different from carbonyl groups of phospholids which appears as a shoulder at $1740 \mathrm{~cm}^{-1}$. The carbonyl ester distribution departs from the proteins and lipids distribution as shown in Figure 7. 
A- Optical image
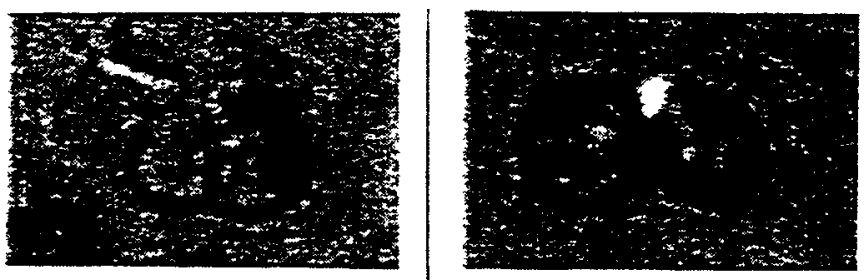

B- Proteins

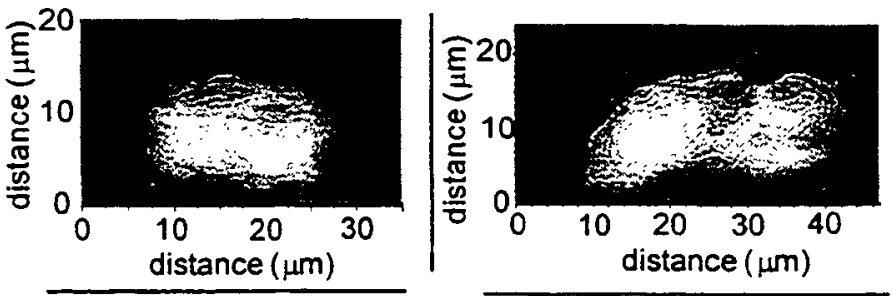

C. Lipids

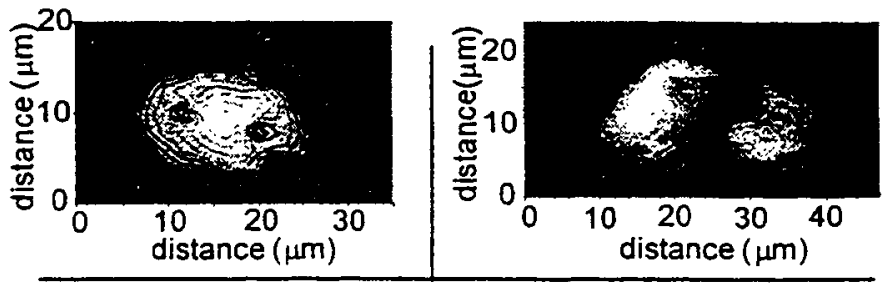

Figure 6. Chemical distribution of proteins and lipids of cells undergoing mitosis. A: Optical image. $\mathrm{B}, \mathrm{C}$ : Proteins and lipids distribution, respectively. The mappings result from the analysis of sets of infrared spectra: left panels (B and C), $18 \times 11$ spectra every $2 \mu \mathrm{m}$ (aperture $5 \times 5 \mu \mathrm{m} 2$ ) and right panels (B and C), $13 \times 9$ spectra every $3 \mu \mathrm{m}$ (aperture $3 \times 3 \mu \mathrm{m}^{2}$ ).

\section{CONCLUSION}

High quality IR spectra and chemical mappings of cells are obtained when using the high brightness synchroton infrared radiation source at the National Synchroton Light Source (NSLS) at Brookhaven National Laboratory, in combination with a Spectra Tech Ir $\mu \mathrm{s} \mathrm{TM}_{\text {scanning microspectrometer. }}$

Reduction of the acquisition time is possible as the instrumental resolution could be degraded by, at least a factor of four, due to the broad lineshape of the $\mathbb{I R}$ bands $\left(30 \mathrm{~cm}^{-1}\right)$. Moreover, the number of co-added scans could also be diminished by a factor of four or more, without decreasing too much the signal-to-noise ratio. Consequently the recording time of the chemical images display on figure 3 can be reduced by a factor of 16 .

The quality of the spectra in the region below $1300 \mathrm{~cm}^{-1}$ should be greatly improved by the use of other substrate like , for example, $\mathrm{KBr}$ window, which are commercially avalaible. As shown on Figure 2, the decrease of the refractive index of $\mathrm{KBr}$ is less important in the region 2.5 to $20 \mu \mathrm{m}$ than for BaF2. The infrared spectrum in the region $1300-500 \mathrm{~cm}^{-1}$ is composed of numerous bands. Some of them have been assigned e.g. the asymmetric $\mathrm{PO}_{2}^{-}$stretching band, the $\mathrm{C}-\mathrm{O}$ streching mode of the $\mathrm{C}-\mathrm{OH}$ groups of serine, threonine, and tyrosine in proteins as well as $\mathrm{C}-\mathrm{O}$ groups of carbohydrates. With the use of the $\mathrm{KBr}$ substrate mapping nucleic acids and $\mathrm{C}-\mathrm{OH}$ groups will be feasible and will bring relevant 
biochemical information. Using a CuGe detector, instead of a MCT one, will also contribute to improve the signal-to-noise ratio in the $1000-600 \mathrm{~cm}^{-1}$ spectral region.

Applications of synchroton infrared microscopy in the field of cellular biology are very promising, for example in comparing different types of cells, and their modification upon drug treatment or radiations. One particular aspect would be the time resolved aspect of such a techrique, which should deserves a particular interest in a near future.
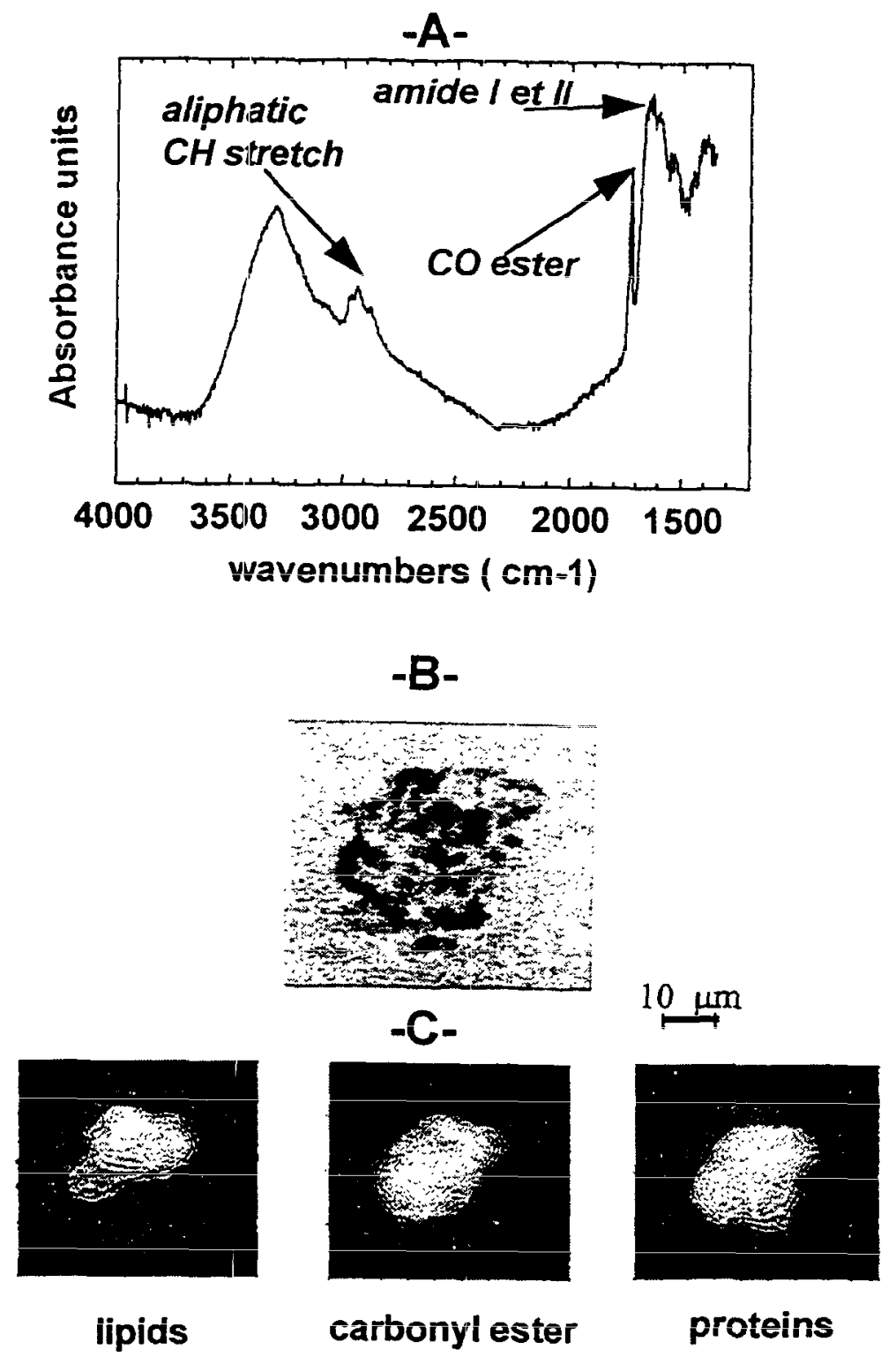

Fig7 : Infrared spectrum and chemical distributions of functional groups of a necrotic cell. A: Infrared spectrum recorded with an aperture of $5 \times 5 \mu \mathrm{m}^{2}$. The instrumental resolution was set at 4 $\mathrm{cm}^{-1}$, and the spectrum displayed is the result of 128 coadded scans. B: Optical image. C: Lipid, carbonyl ester group, and protein distributions. The chemical distributions are the result of the analysis of $15 \times 14$ spectra, each spectrum is recorded every $3 \mu \mathrm{m}$ step using an aperture size of $5 \times 5$ $\mu \mathrm{m}^{2}$ and a $4 \mathrm{~cm}^{-1}$ resolution (128 scans per spectrum). 


\section{REFERENCES}

1. P.R Griffiths, J.A. de Haseth, "Fourier Transform Infrared Spectroscopy", John Wiley and Sons Eds., New York, 1986.

2. P.T.T. Wong and B. Rigas, Appl. Spectrosc. 44, 1715, 1990.

3. P.T.T. Wong and B. Rigas, Appl. Spectrosc. 4, 1563 (1991).

4. P.T.T. Wong, RK. Wong, T.A. Caputo, T.A. Godwin, and B. Rigas, Proc. Natl. Acad. Sci. (USA) 88, 10988, 1991.

5. G.L. Carr, J.A. Reffner, G.P. Williams, Rev. Sci. Instrum. 66, 1490, 1995.

6. G.L. Carr, M. Hanfland, G.P. Williams, Rev. Sci. Instrum. 66, 1643, 1995.

7. S. Brunati, C. Miossec, C. Mathiot, J. Moncuit, S. Amigorena, J.-L. Teillaud, W.H. Fridman, Mol. Immunol., 25, 1133, 1988.

8. P.T.T. Wong, E.D. Papavassiliuo, B. Rigas, Appl. Spectrosc. 45, 1563, 1991.

9. H.Susi and D.M. Byler, Methods Enzymol. 130, 290, 1986.

10. F. Siebert, Methods Enzymol. 246, 501, 1995; W.L. Peticolas, ibid. 246, 389, 1995.

11. The Infrared Handbook Office of Naval Research Department of the Navy, Editors: Wolfe and Zissis, 1985. 